\title{
BCL-2 family member BOK is widely expressed but its loss has only minimal impact in mice
}

\author{
F Ke ${ }^{1,2}$, A Voss $^{1,2}$, JB Kerr ${ }^{3}$, LA O'Reilly ${ }^{1,2}$, L Tai ${ }^{1}$, N Echeverry ${ }^{1,4}$, P Bouillet $^{1,2}$, A Strasser ${ }^{\star, 1,2,5}$ and T Kaufmann ${ }^{1,4,5}$
}

BOK/MTD was discovered as a protein that binds to the anti-apoptotic Bcl-2 family member MCL-1 and shares extensive aminoacid sequence similarity to BAX and BAK, which are essential for the effector phase of apoptosis. Therefore, and on the basis of its reported expression pattern, BOK is thought to function in a BAX/BAK-like pro-apoptotic manner in female reproductive tissues. In order to determine the function of BOK, we examined its expression in diverse tissues and investigated the consequences of its loss in $\mathrm{Bok}^{-I-}$ mice. We confirmed that Bok mRNA is prominently expressed in the ovaries and uterus, but also observed that it is present at readily detectable levels in several other tissues such as the brain and myeloid cells. Bok ${ }^{-l-}$ mice were produced at the expected Mendelian ratio, appeared outwardly normal and proved fertile. Histological examination revealed that major organs in $\mathrm{Bok}^{-1-}$ mice displayed no morphological aberrations. Although several human cancers have somatically acquired copy number loss of the Bok gene and BOK is expressed in B lymphoid cells, we found that its deficiency did not accelerate lymphoma development in $\mathrm{E} \mu-M y c$ transgenic mice. Collectively, these results indicate that Bok may have a role that largely overlaps with that of other members of the Bcl-2 family, or may have a function restricted to specific stress stimuli and/or tissues.

Cell Death and Differentiation (2012) 19, 915-925; doi:10.1038/cdd.2011.210; published online 27 January 2012

The BCL-2 family of proteins are major regulators of apoptosis, which according to structure and function can be divided into three groups. ${ }^{1}$ One group (including BCL-2, BCL$X_{L}, B C L-W, M C L-1$ and $A 1$ ) inhibits apoptosis, whereas the other two groups - namely the BAX/BAK-like subfamily ${ }^{2}$ and the BH3-only proteins (including BIM, NOXA, PUMA, BIK, HRK, BAD and BID) ${ }^{3}$ promote apoptosis. Complex interactions between the pro-survival and the two sub-groups of proapoptotic members determine whether a cell lives or dies. The BH3-only proteins are essential for initiation of apoptosis signalling and are activated in a cell death stimulus as well as cell type specific manner. ${ }^{1,3,4} \mathrm{BAX}$ and BAK on the other hand are essential for mitochondrial outer membrane permeabilisation (MOMP), which unleashes the caspase cascade for cellular demolition. ${ }^{1}$ They appear to be activated by direct binding by certain BH3-only proteins, ${ }^{2,4}$ as well as (indirectly) by liberation from pro-survival BCL-2-like proteins. 5,6

BAX and BAK have overlapping actions in the 'mitochondrial' apoptotic pathway. ${ }^{7}$ Mice lacking either BAK or BAX alone are largely normal (with the exception of sterility of $\mathrm{Bax}^{-1-}$ males), but Bax/Bak doubly deficient mice show remarkable developmental abnormalities, including persistent inter-digital webbing and brain malformations that are the likely cause of the early post-natal death of most of these animals. ${ }^{7}$ Fibroblasts and lymphocytes from $\mathrm{Bax}^{-1-} \mathrm{Bak}^{-1-}$ mice are profoundly resistant to a broad range of apoptotic stimuli, such as cytokine deprivation, DNA damage ${ }^{7,8}$ and even enforced expression of $\mathrm{BH} 3$-only proteins, ${ }^{9,10}$ although, as expected, ${ }^{11}$ not to 'death receptor'-induced killing. Intriguingly, a very small number ( $<10 \%$ on a C57BL/6 background) of Bax/Bak doubly deficient mice survive to early adulthood and apart from a remarkable lymphadenopathy, ${ }^{8}$ many of their organs, such as the kidney, liver, heart and lungs display no overt developmental defects and function normally. ${ }^{7}$ This may indicate that an additional protein can function in a BAX/BAK-like manner. Alternatively, an apoptotic process independent of the BAX/ BAK-dependent 'Bcl-2 regulated' pathway or a non-apoptotic process (e.g., necroptosis) may ensure developmentally programmed cell death to sculpt tissues in $\mathrm{Bax}^{-1-} \mathrm{Bak}^{-1-}$ mice.

\footnotetext{
${ }^{1}$ Molecular Genetics of Cancer Division, The Walter and Eliza Hall Institute of Medical Research, Melbourne, Victoria, Australia; ${ }^{2}$ Department of Medical Biology, The University of Melbourne, Melbourne, Victoria, Australia and ${ }^{3}$ Department of Anatomy and Developmental Biology, Monash University, Clayton, Victoria, Australia ${ }^{*}$ Corresponding author: A Strasser, Molecular Genetics of Cancer Division, The Walter and Eliza Hall Institute of Medical Research, $1 \mathrm{G}$ Royal Parade, Parkville, Victoria 3052, Australia. Tel: + 6139345 2555; Fax: + 6139347 0852; E-mail: strasser@wehi.edu.au

${ }^{4}$ Current address: Institute of Pharmacology, University of Bern, Bern, Switzerland.

${ }^{5}$ These authors share senior authorship.

Keywords: apoptosis; BOK; BAX; BAK; BCL-2

Abbreviations: APC, allophycocyanin; ATP5a1, ATP synthase $\mathrm{H}+$ transporting mitochondrial F1 complex alpha subunit 1; bp, basepair; BM, bone marrow; cDNA, complementary deoxyribonucleic acid; CC, corpus callosum; Ctx, cerebral cortex; ddCT, delta-delta CT; DMEM, Dulbecco's modified Eagle medium; DNA, deoxyribonucleic acid; EDTA, ethylenediaminetetraacetic acid; ESC, embryonic stem cells; FACS, fluorescence activated cell sorting; FCS, fetal calf serum; FITC, fluorescein isothiocyanate; FasL, Fas ligand; GAPDH, glyceraldehyde 3-phosphate dehydrogenase; h, hour; $\mathrm{HCl}$, hydrochloric acid; HIF1 $\alpha$, hypoxia-inducible factor $1 \propto$ subunit; LN, lymph nodes; mac, macrophages; neu, neutrophils; mg, milligram; $\mu \mathrm{g}$, microgram; $\mathrm{mL}$, milliliter; $\mu \mathrm{L}$, microlitre; mM, millimolar; $\mathrm{kDa}$, kilo Dalton; MOMP, mitochondrial outer membrane permeabilisation; $\mathrm{mRNA}$, messenger ribonucleic acid; $\mathrm{NaCl}$, sodium chloride; PI, propidium iodide; qPCR, quantitative polymerase chain reaction; R-PE, red phycoerythrin; SCNA, somatically acquired copy number alterations; SD, standard deviation; SDS-PAGE, sodium dodecyl sulphate polyacrylamide gel electrophoresis; SEM, standard error of the mean; Se, septum; slg, surface immunoglobulin; Str, Striatum; SV40, simian virus 40; Ter119 + cells, erythroid cells expressing the Ter119 lineage marker; WBC, white blood cells; wt, wild-type

Received 09.9.11; revised 12.12.11; accepted 15.12.11; Edited by C Borner; published online 27.1.12
} 
BOK (also known as MTD) was discovered as a protein that bound to pro-survival MCL- 1 by screening of a rat ovarian fusion cDNA library in the yeast 2 -hybrid system. ${ }^{12}$ Mouse BOK (mBOK) shows most extensive amino-acid sequence homology to $\operatorname{mBAK}(87 \%)$ and $\operatorname{mBAX}(73 \%)$, with particularly strong conservation across the $\mathrm{Bcl}-2$ Homology $(\mathrm{BH})$ domains and the trans-membrane region. ${ }^{12}$ Consequently, it is widely assumed that BOK exerts a BAX/BAK-like pro-apoptotic function. In support of this hypothesis, it has been reported that over-expression of BOK can induce apoptosis in certain mammalian cell lines and primary neurons from the dorsal root ganglia of neonatal rats. ${ }^{12-14}$ Moreover, in placental samples from pregnant women suffering from pre-eclampsia, Bok expression was found to be associated with abnormally elevated trophoblast cell death. ${ }^{15,16}$ Interestingly, somatically acquired loss of copy number of the Bok gene has been detected in diverse human cancers, ${ }^{17}$ indicating that $\mathrm{BOK}$ may function as a tumour suppressor.

To determine the function of Bok, we have examined its expression in diverse tissues and cell types and generated Bok knockout $\left(\mathrm{Bok}^{-1-}\right)$ mice. Our results show that Bok is expressed most prominently in reproductive tissues and the brain, but is also present at lower levels in most other tissues. However, Bok-deficient mice were of normal appearance, fertile, displayed normal tissue architecture and their lymphoid and myeloid cells were normally sensitive to a range of apoptotic stimuli. These findings may indicate that Bok exerts a function that is largely overlapping with those of $\mathrm{BAX}$ and $\mathrm{BAK}$, and may feature most prominently in reproductive organs and the brain, the tissues in which it is most highly expressed.

\section{Results}

Bok mRNA is expressed in a wide range of tissues. Earlier studies reported that Bok shows restricted expression in reproductive tissues. ${ }^{12}$ Consistent with these findings, qPCR analysis demonstrated that Bok mRNA expression was most abundant in the uterus and ovaries of healthy, adult (14-week old) C57BL/6 female mice, but relatively high levels were also seen in the brain $(\sim 1.8$-fold less compared with the uterus) followed by the spleen, lung, stomach, small intestine and kidney (Figure 1a). Lower, but still readily detectable levels of Bok mRNA were found in the liver, thymus and lymph nodes, with the weakest expression observed in the heart and bone marrow (BM) (Figure 1a). Western blotting using polyclonal rabbit antibodies raised against a mBOK-derived polypeptide revealed that BOK protein could be readily detected in tissues that expressed high levels of Bok mRNA (Figure 1b).

qPCR analysis of FACS sorted leucocyte sub-populations revealed readily detectable, albeit relatively low, levels of $B o k$ mRNA in T-cell subsets $\left(\mathrm{CD} 4^{+} \mathrm{CD}^{-}, \mathrm{CD}^{-} \mathrm{CD}^{+}\right.$, $\mathrm{CD}^{-}{ }^{-} \mathrm{CD} 8^{-}$and $\mathrm{CD} 4{ }^{+} \mathrm{CD}^{+}$) from the thymus, $\mathrm{B}$ and $\mathrm{T}$ cells from lymph nodes, and $\sim$ five-fold higher expression in Ter119 ${ }^{+}$erythroid cells, macrophages and neutrophils from the $\mathrm{BM}$ of (wt) C57BL/6 mice (Figure 1c). Western blot
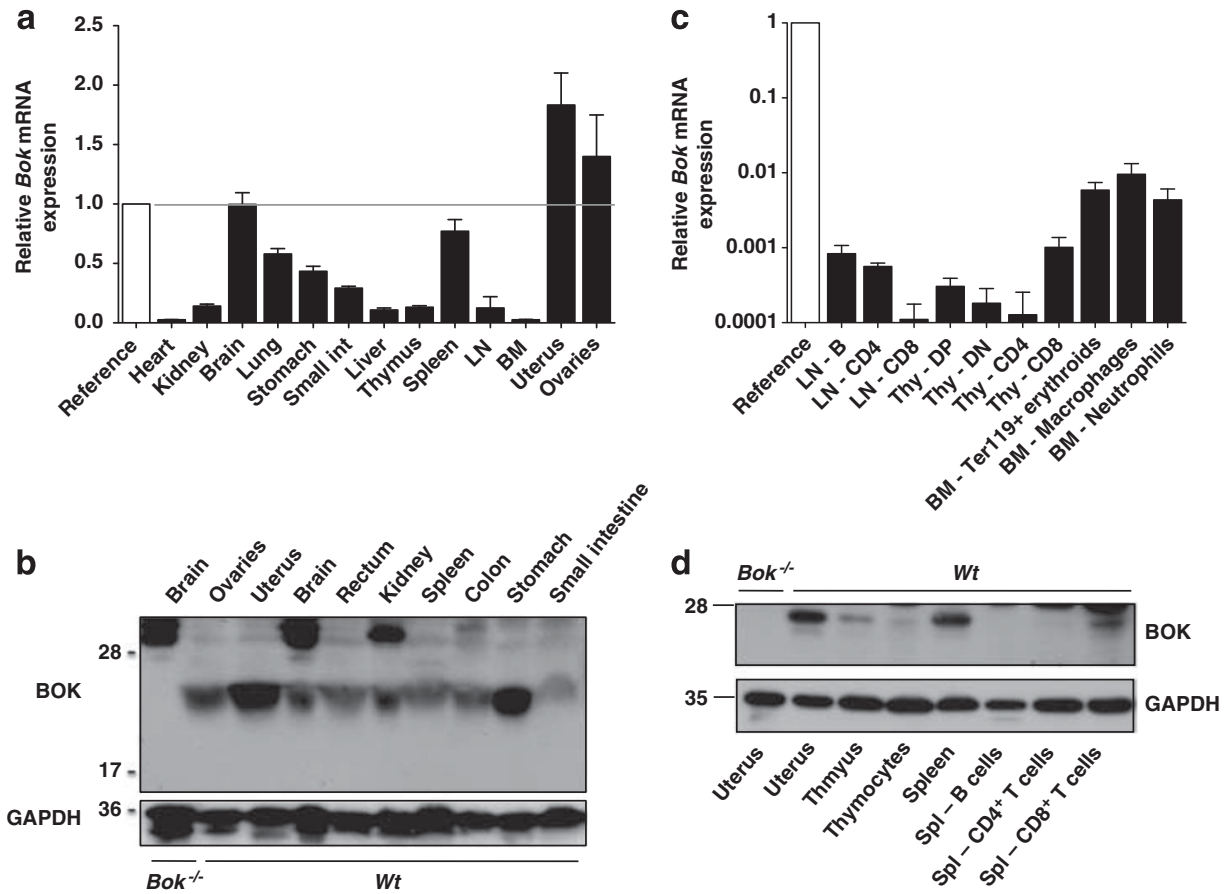

Figure 1 Bok is expressed in a broad range of tissues and hematopoietic cell types and its levels are not affected by loss of Bax and/or Bak. (a) The levels of BokmRNA in different tissues of adult (12-16-week old) C57BL/6 (wt) mice are expressed in relation to a fixed reference sample (wt brain). (b) Western blot analysis of major organs from C57BL/6 (wt) mice for BOK expression. Brain extracts from Bok ${ }^{-1-}$ animals were used as a negative control. Probing with an antibody to GAPDH was used as a loading control. (c) BokmRNA expression in FACS-sorted hematopoietic cell populations from the LN, thymus (thy), and BM in comparison with the reference sample (wt brain; white bar). (d) BOK protein expression in the indicated leukocyte populations was determined by western blot analysis. Cells isolated from the uterus of wt and Bok ${ }^{-1-}$ mice were used as a positive and negative control, respectively, and probing of the membranes with an anti-GAPDH antibody served as a loading control 
analysis revealed the presence of BOK protein in splenic $\mathrm{CD}^{+} \mathrm{T}$ cells, thymocytes (Figure 1d) and bone-marrow derived granulocytes and macrophages (data not shown). Higher levels of BOK protein were observed in total extracts from thymus, spleen and lymph nodes (LN) compared with isolated lymphocyte sub-populations, indicating that non-hematopoietic cells within these tissues express more BOK than lymphoid cells (Figure 1d).

Given the prevailing view that Bok may exert a function akin to those of BAX and BAK, we explored whether loss of either Bax, Bak or both impacted on the expression of Bok. qPCR analysis for Bok mRNA expression comparing extracts of 13 organs from $\mathrm{Bax}^{-1-}, \mathrm{Bak}^{-/-}$and $\mathrm{Bax}^{-1-} \mathrm{Bak}^{-1-}$ mice with those of wt controls revealed that loss of BAK, BAX or both proteins did not significantly alter Bok mRNA levels (Supplementary Figure 1a), with the possible exception of LN from $\mathrm{Bax}^{-1-}$ mice, which displayed slightly higher levels of Bok mRNA (wt $=0.125, \mathrm{Bax}^{-1-}=0.473, P=0.0349$ ). Western blot analysis showed that most tissues from $\mathrm{Bax}^{-1-}$ and $\mathrm{Bak}^{-/}$mice contained similar levels of BOK protein as those from wt animals, although there may be an increase in $B O K$ in the rectum and ovaries from BAX- and BAK-deficient mice (Supplementary Figure 1b).

Generation of $\mathbf{B o k}^{-1-}$ mice. The Bok gene was targeted for deletion by introducing LoxP sites that flank half of exon 1 and exon 2, which contains the ATG start site (Figure 2a). Two independent lines of BOK-deficient mice were produced

a
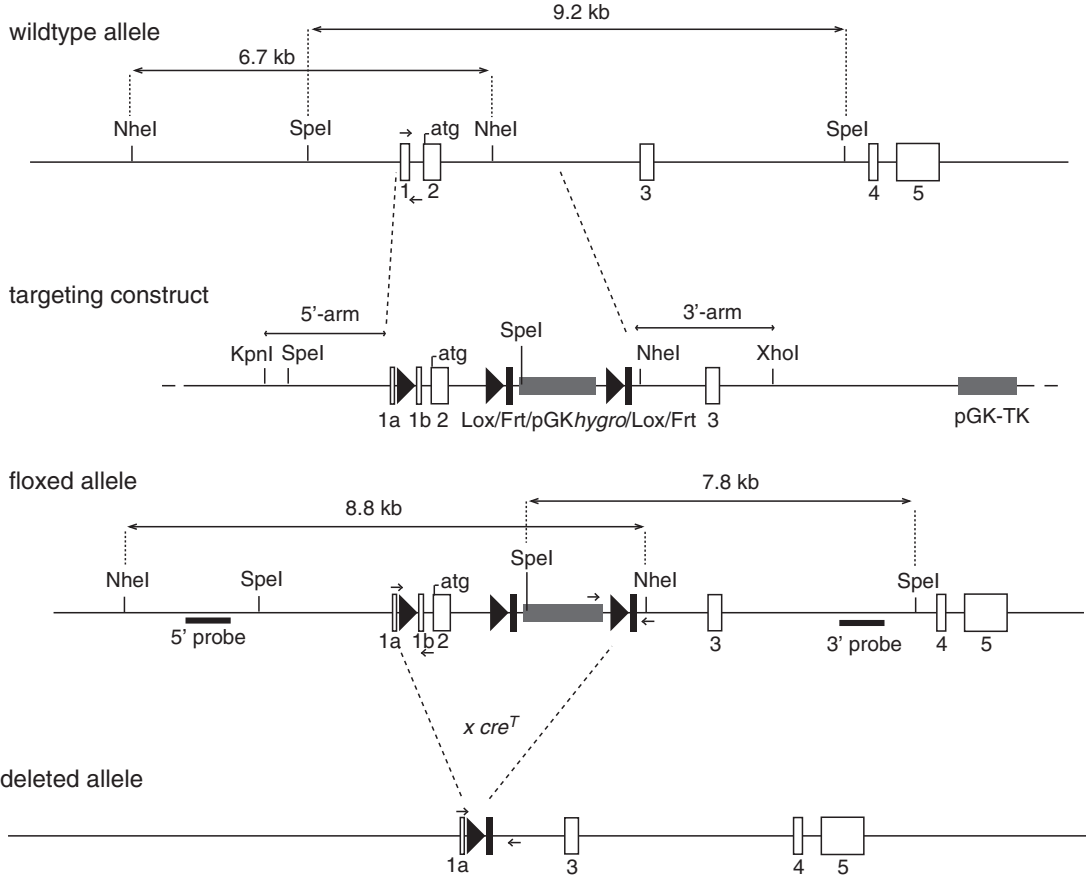

b

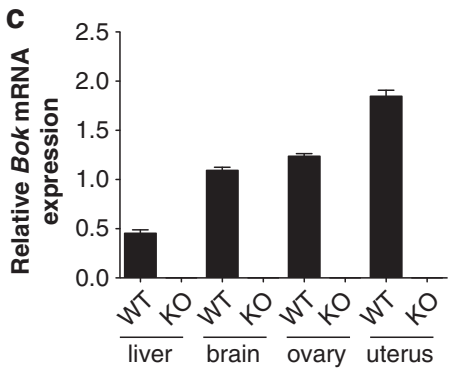

d

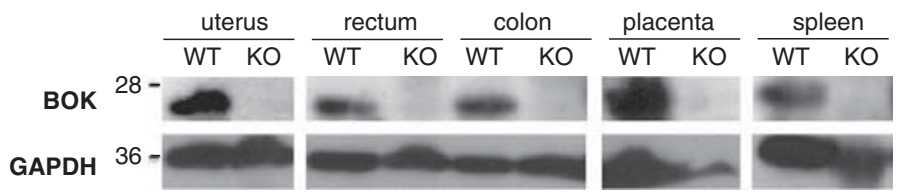

Figure 2 Targeting of the Bok locus. (a) Schematic diagram depicting the wt Bok allele and the targeting construct. Dashed lines demarcate the targeted locus in the Bok gene. The locations of $5^{\prime}$ and $3^{\prime}$ external probes used for Southern blot analysis are indicated. (b) All mice were genotyped before examination. A successful targeted deletion of Bokyielded a 383-bp PCR product, whereas the wt allele produced a 150-bp band when subjected to gel electrophoresis. (c) Bok mRNA levels in wt and Bok ${ }^{-1-}$ mice were determined by qPCR analysis. Data represent the mean \pm S.D from three mice of each genotype. (d) The absence of BOK protein in mutant mice was confirmed by western blot analysis of Bok ${ }^{-1-}$ tissue extracts along with corresponding tissues from wt controls. Membranes were incubated with rabbit anti-BOK polyclonal antibodies and subsequently with a monoclonal antibody to GAPDH (loading control) 
by crossing $\mathrm{Bok}^{f l /+}$ mice with $\mathrm{Cre}^{\mathrm{fl}}$-deleter ${ }^{+/ t g}$ females to achieve excision of the targeted region. Intercrosses of $\mathrm{Bok}^{+/-}$mice generated $\mathrm{Bok}^{-/-}, \mathrm{Bok}^{+/-}$and $\mathrm{Bok}^{+/+}$ offspring, which were genotyped before being used for examination (Figure 2b). qPCR analysis using primers located in the region of the Bok gene that was not deleted revealed that no Bok mRNA could be detected in tissues from Bok ${ }^{-1-}$ mice (Figure 2c). Similarly, western blot analysis revealed a $\sim 23-\mathrm{kDa}$ band corresponding to the predicted molecular weight of BOK only in tissues from wt mice, but not those from $\mathrm{Bok}^{-1-}$ animals (Figure 2d). Additional western blot analysis of several tissues revealed that loss of BOK did not cause marked alterations in the levels of BAX or BAK proteins (Supplementary Figure 2). Together, these results demonstrated successful inactivation of the Bok gene and that this did not affect the expression of BAX/BAK.

Bok-deficient mice develop normally and organs in Bok $^{-I-}$ mice appear normal. Intercrosses of $\mathrm{Bok}^{+/-}$mice produced $\mathrm{Bok}^{-/-}, \mathrm{Bok}^{+/-}$and $\mathrm{Bok}^{+/+}$offspring at the expected Mendelian ratio (25:51:23), and $\mathrm{Bok}^{-/-}$mice appeared outwardly normal and healthy when monitored for up to 18 months of age. Moreover, $\mathrm{Bok}^{-1-}$ mice of both genders could produce healthy offspring, indicating that BOK is dispensable for normal embryonic development and female or male fertility.

As Bok mRNA is prominently expressed in female reproductive tissues (Figure 1a), ${ }^{12}$ we examined serial sections of ovaries from early postnatal (day 11), adult (14 weeks) and aged (7 and 12 months) females. Gross histological analysis revealed that ovaries from $\mathrm{Bok}^{-/-}$ females were indistinguishable from those of age-matched wt controls. Folliculogenesis was normal and there was no evidence of dysmorphic structures or pathology (Figure 3a). Quantification of the different follicle populations from serial sections showed no significant differences in follicle numbers between wt and $\mathrm{Bok}^{-/-}$ovaries (Figure 3b). Histological examination of uteri from 14-week-old $\mathrm{Bok}^{-1-}$ female mice revealed no obvious abnormalities in the luminal epithelium, stroma, glandular epithelium and myometrial layers (Figure 3c).

Subsequently, we examined whether BOK loss might give rise to phenotypic aberrations in the brain, given that it is expressed relatively highly in this organ (Figure 1) and that loss of its relative, BAX, causes abnormal accumulation of neurons in the facial nuclei. ${ }^{18}$ Microscopic evaluation of serial sections revealed that brains from $\mathrm{Bok}^{-1-}$ animals appeared normal (Figure 4a), and no obvious accumulation of motor neurons in the facial nucleus was observed (Figure $4 \mathrm{~b}$ ). A side-by-side comparison of brain sections suggested that $B o k^{-l-}$ mice may have a slightly $(\sim 5 \%)$ larger brain, however, there was no statistically significant difference when brain weights were compared.

Further histological analysis of eighteen other tissues from 14- to 16-week-old $\mathrm{Bok}^{-1-}$ mice, including the kidney, liver, testes, lymph nodes, spleen, thymus and pancreas, did not reveal any obvious abnormalities (Supplementary Figure 3). Intriguingly, $\mathrm{Bok}^{-1-}$ females displayed a significant, albeit relatively minor, increase in spleen $(w t=68.43 \pm$ $\left.3.123 \mathrm{mg} \mathrm{Bok}^{-1-}=85.57 \pm 5.618 \mathrm{mg}, P=0.0205\right)$ and thymus (wt $=55.71 \pm 2.670 \mathrm{mg}$, Bok $\left.^{-1-}=66.57 \pm 1.901 \mathrm{mg}, P=0.0062\right)$ weights (Figure $5 \mathrm{a}$ ), but no significant difference was observed in males (Figure 5b). Taken together, these results demonstrate that on its own, BOK is dispensable for normal mouse development and ageing.

Lymphoid organs of adult $\mathrm{Bok}^{-1-}$ mice have normal hematopoietic cell subset composition. As qPCR and western blot analyses revealed the presence of Bok mRNA and BOK protein, respectively, in lymphoid and particularly myeloid cell subsets (Figure 1), we investigated the impact of Bok deficiency on the development and homeostasis of the hematopoietic compartment by flow cytometric analysis. In particular, we wanted to find out whether the increase in thymus and spleen weights observed in $\mathrm{Bok}^{-1-}$ females (Figure 5a) could be attributed to the accumulation of a specific leucocyte sub-population. Total thymic cellularity of $B o k^{-1-}$ mice as well as their content of CD4 ${ }^{-} \mathrm{CD} 8^{-}$pro-T cells, $\mathrm{CD}^{+}{ }^{+} \mathrm{CD} 8^{+}$immature and $\mathrm{CD} 4^{+} \mathrm{CD}^{-}$as well as $\mathrm{CD}^{-} \mathrm{CD}^{+}$mature thymocytes were comparable to those of wt controls (Figure 6a). Similarly, spleens from Bok ${ }^{-1-}$ mice contained normal numbers of leucocytes overall, immature and mature $\mathrm{B}$ cells, $\mathrm{CD} 4^{+} \mathrm{CD} 8^{-}$as well as $\mathrm{CD} 4^{-} \mathrm{CD} 8^{+}$ mature $T$ cells, neutrophils, macrophages and Ter119 ${ }^{+}$ erythroid cells (Figure 6b). Loss of Bok also had no impact on the numbers of pro- $B$, pre-B, immature and mature $B$ cells, neutrophils, macrophages and nucleated erythroid cells in the BM (Figure 6c). Finally, Bok ${ }^{-1-}$ and wt mice had comparable numbers of lymphocytes, monocytes, neutrophils, eosinophils and basophils in their blood (Figure 6d). These results demonstrate that loss of Bok does not cause defects in the development or homeostasis of hematopoietic cells.

Bok-deficient lymphoid and myeloid cells respond normally to apoptotic stimuli. The absence of proapoptotic Bcl-2 family members, such as Bim, ${ }^{19}$ Puma $^{20}$ or combined deficiency for $B a x$ and $B a k^{7,8}$ render hematopoietic cells resistant to apoptotic stimuli. As Bok mRNA and protein could be detected in several hematopoietic cell subsets (Figure 1), we investigated whether the loss of Bok could confer a survival advantage upon lymphoid or myeloid cells in the presence of various apoptotic stimuli. FACS-sorted $\mathrm{slg}^{+} \mathrm{B}$ cells, $\mathrm{CD}^{+}{ }^{+} \mathrm{CD}^{-}$as well as $\mathrm{CD}^{-} \mathrm{CD}^{+}$mature $\mathrm{T}$ cells from lymph nodes, $\mathrm{CD}^{+}{ }^{+} \mathrm{CD}^{+}{ }^{+}$immature thymocytes and bone marrowderived neutrophils were cultured in the presence of dexamethasone, etoposide, Fas ligand, the $\mathrm{BH} 3$ mimetic compound ABT-737 or in simple culture medium (Dulbecco's modified Eagle's medium (DMEM) +10\% FCS) lacking cytokines to mimic cytokine deprivation. These cytotoxic insults all rapidly killed the wt hematopoietic cell populations, but loss of BOK failed to confer any protection from these stressors (Figure 7). These results show that on its own, BOK is dispensable for apoptosis induced by a diverse range of death stimuli, at least in lymphoid and myeloid cells.

Loss of Bok does not accelerate Iymphoma development in $E \mu-m y c$ transgenic mice. Somatically acquired copy number alterations involving the Bok gene 
a
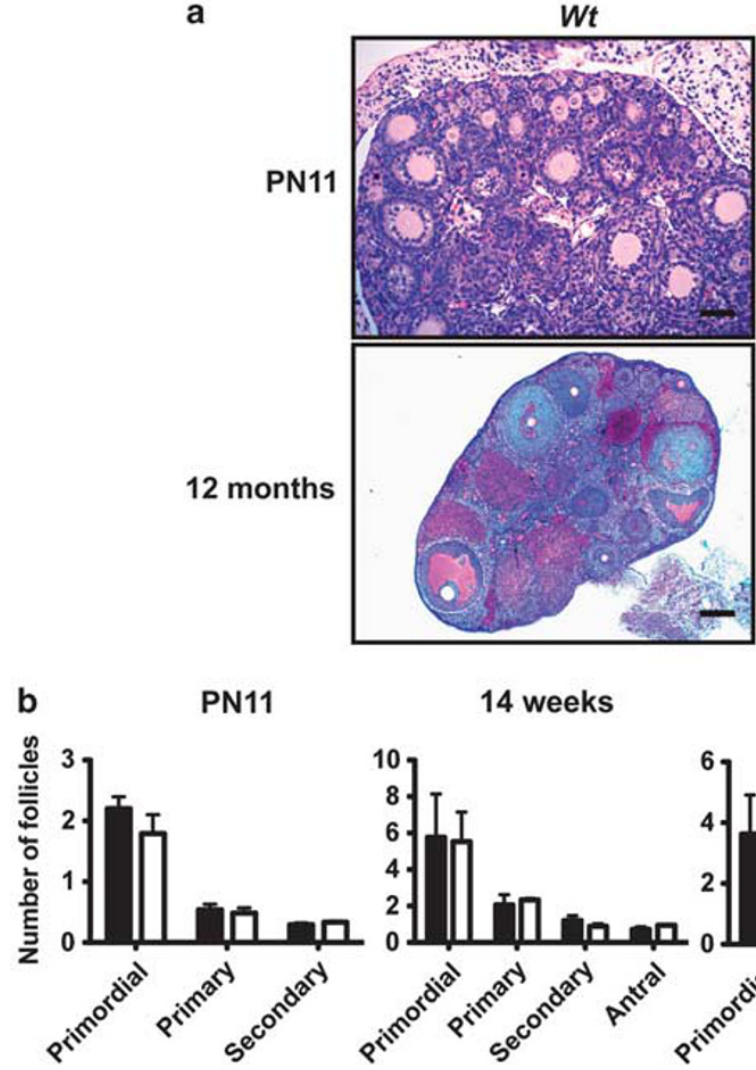

14 weeks

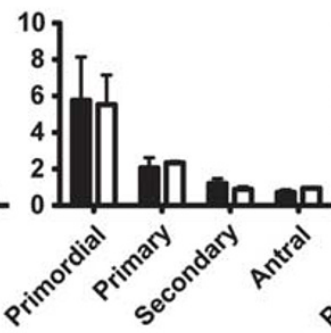

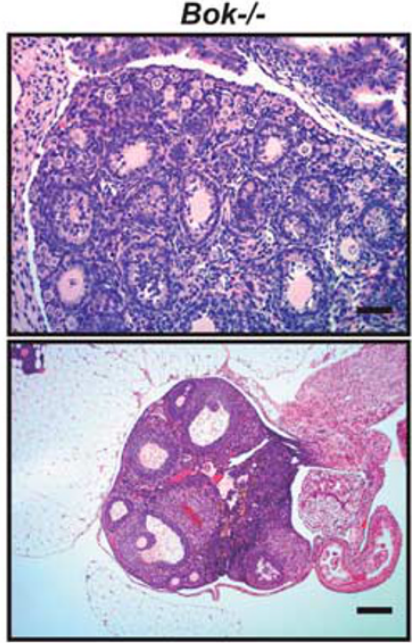

7 months

1 year
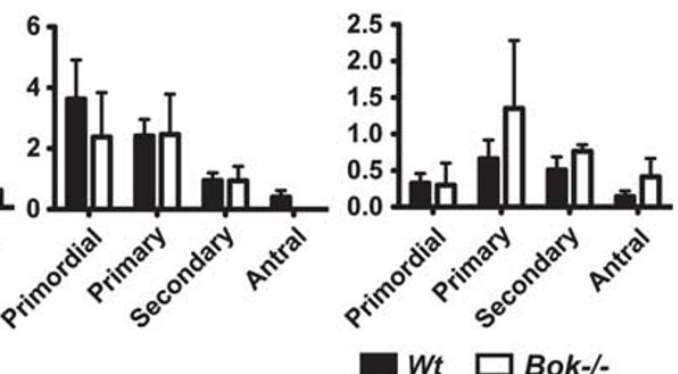

C
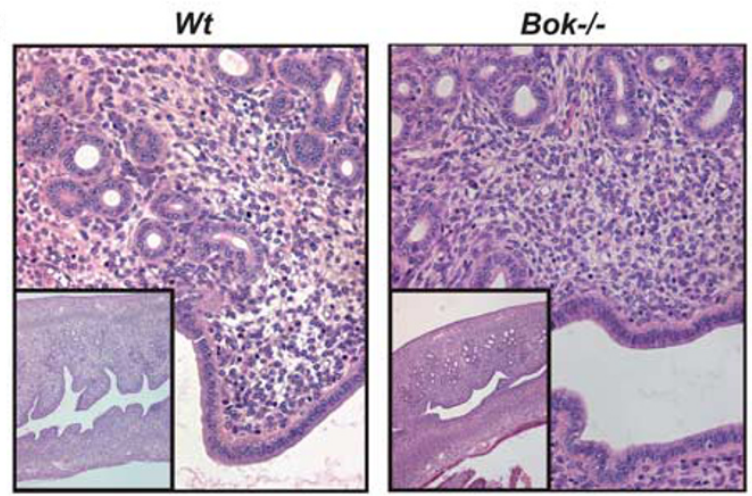

Figure 3 Reproductive organs in female Bok ${ }^{-1-}$ mice are of normal appearance. Histological sections from ovaries and uteri of 14-16-week-old Bok ${ }^{-1-}$ and wt mice were stained with haematoxylin plus eosin and examined by microscopic analysis. (a) Ovaries of wt and Bok ${ }^{-1}$ mice at post-natal day 11 (magnification bar $=50 \mu \mathrm{m}$ ) and 12 months of age (magnification bar $=200 \mu \mathrm{m}$ ). Images of 14 week- and 7-month-old ovaries were also examined but are not shown. (b) Graphs depict the mean score for each follicle type in the ovary, which are expressed as numbers per $\mathrm{mm}^{2}$. Data represent the mean \pm S.E.M. of follicle numbers from 3-6 mice of each genotype. (c) Images showing the morphology of the uterus from wt and $\mathrm{Bok}^{-1-}$ mice shown at $\times 5$ (inset) and $\times 20$ magnification

have been detected in a range of human cancers at relatively high frequency, ${ }^{17}$ indicating that BOK may function as a tumour suppressor. Loss of pro-apoptotic BAX, ${ }^{21} \mathrm{BIM}^{22}$ or PUMA, ${ }^{23-25}$ accelerated pre-B/B lymphoma development in $E \mu-m y c$ transgenic mice, which over-express the onco-protein c-MYC that deregulates cell proliferation in the B-lymphoid lineage under control of the $\mathrm{lgH}$ gene enhancer $(E \mu){ }^{26}$

Interestingly, qPCR and western blot analyses revealed that pre-B cells from 5-week-old E $\mu$-myc mice (pre-leukaemic stage) had significantly lower levels of Bok mRNA and BOK protein, respectively, compared with pre-B cells from wt control animals (wt $=0.0421, E \mu-m y c=0.0201, P=0.0092$; Supplementary Figure 4). Loss of one or both alleles of Bok did, however, not significantly affect pre-B/B lymphoma development in $E \mu$-myc transgenic mice (median lymphomafree survival: $E \mu-m y c: 107$ days; $n=16, E \mu-m y c / B_{0}{ }^{+/-}$: 132 days; $n=57, \quad E \mu-$ myc/Bok $^{-/}: 121$ days; $\left.n=25\right)$ (Figure 8a). Moreover, post mortem analysis on sick, tumour-burdened animals revealed that spleen, thymus and 

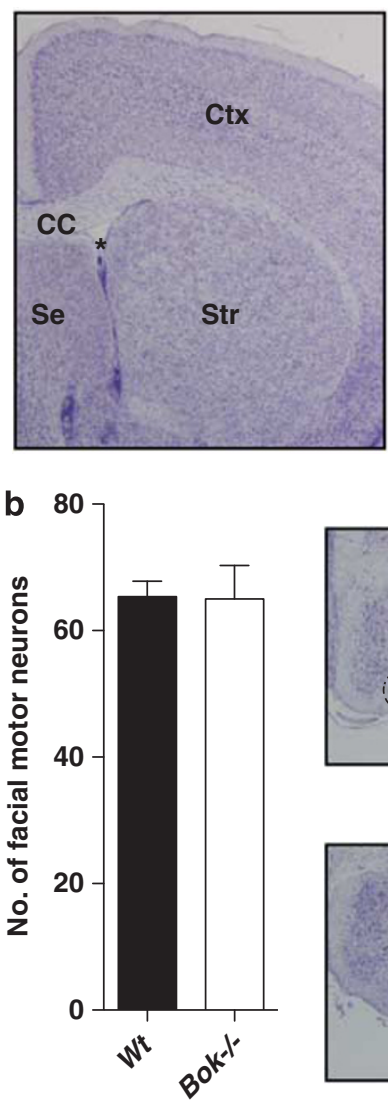

Figure 4 Brains in $\mathrm{Bok}^{-/-}$mice are of normal appearance. (a) Serial sections of the brain were obtained and stained with crystal violet. (Top panel) Images include the cerebral cortex (Ctx), corpus callosum (CC), septum (Se), striatum (Str), and lateral ventricle $\left(^{*}\right)$. (Bottom panel) Transverse sections of the facial nucleus (highlighted with dotted lines) in wt and Bok ${ }^{-1-}$ animals. (b) The number of facial motor neurons in brains from Bok ${ }^{-1-}$ mice were quantified and compared with ageand sex-matched wt controls. Data represent means \pm S.E.M. from 3-4 mice of each genotype

lymph node weights, as well as total white blood cells counts were not significantly different between control $E \mu-m y c$, $\mathrm{E} \mu-\mathrm{myc} / \mathrm{Bok}^{+/-}$and $\mathrm{E} \mu-\mathrm{myc}_{\mathrm{B}} \mathrm{Bok}^{-1-}$ mice (Figures $8 \mathrm{~b}-\mathrm{e}$ ), demonstrating that the loss of BOK had no impact on disease severity. Taken together, these results demonstrate that $\mathrm{BOK}$ does not function as a suppressor of C-MYC driven pre-B/Bcell lymphoma development.

\section{Discussion}

BOK was originally discovered as a protein that bound to MCL-1 in a yeast 2-hybrid library screen of a rat ovarian gene expression library. ${ }^{12}$ On the basis that BOK shares most extensive amino-acid sequence similarity with BAX and BAK, it is widely believed that it functions in a BAX/BAK like manner, that is, in the activation of the effector phase of apoptosis that is characterised by MOMP and unleashing of the caspase cascade. However, BOK is one of the most poorly studied members of the wider BCL-2 family and there is no definitive understanding of its role in normal physiology or conditions of pathological stress. To determine the function of BOK, we
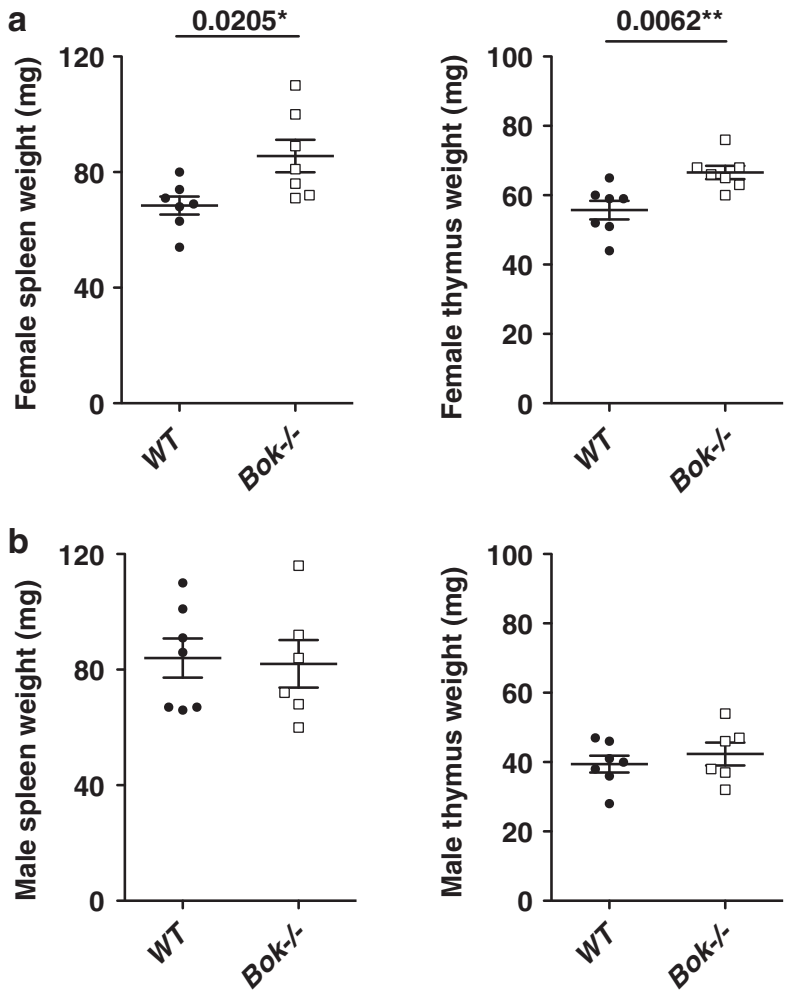

Figure $5 \mathrm{Bok}^{-1-}$ female but not male mice have abnormally increased thymus and spleen weight. (a) Spleens and thymi from 9-12-week-old female and (b) male $B \mathrm{~K}^{-1-}$ and control wt mice were weighed. Each data point represents an individual mouse ( $n=7$ for each genotype and gender). Statistically significant differences are indicated. ${ }^{*} P<0.05,{ }^{*} P<0.01$

performed an extensive analysis of its expression in diverse tissues and cell types, and examined the consequences of its loss in BOK-deficient mice.

Consistent with previous findings, we observed prominent Bok mRNA and protein levels in the ovaries and uterus. BOK was, however, also readily detected in many additional organs, such as the brain, spleen, lung and stomach. This indicates that BOK may have a wider role rather than being limited to the female reproductive system as previously anticipated. $^{12}$ Further qPCR and western blot analyses showed that cells from $\mathrm{Bax}^{-1-}, \mathrm{Bak}^{-1-}$ and even those from $\mathrm{Bax}^{-1-} \mathrm{Bak}^{-1-}$ animals expressed similar levels of Bok mRNA and BOK protein as wt mice. These results indicate that loss of $\mathrm{BAX}$ or BAK, or even both pro-apoptotic multi-BH domain proteins do not exert pressure for a compensatory increase in Bok expression. This does, however, not exclude the possibility for functional overlap between BOK with BAX/ $B A K$, given that despite the well-established functional overlap between $\mathrm{BAX}$ and $\mathrm{BAK}, \mathrm{Bax}^{-1-}$ cells express normal levels of BAK and $\mathrm{Bak}^{-1-}$ cells express normal levels of BAX (e.g. Lindsten et al. ${ }^{7}$ ).

Earlier studies trying to define the function of Bok have employed over-expression systems in normal or transformed cells. $^{12,14}$ These experiments showed that BOK over-expression could trigger apoptosis either on its own or enhance apoptosis elicited by treatment with certain cytotoxic drugs. Our analysis of Bok-deficient mice represent to our knowledge 

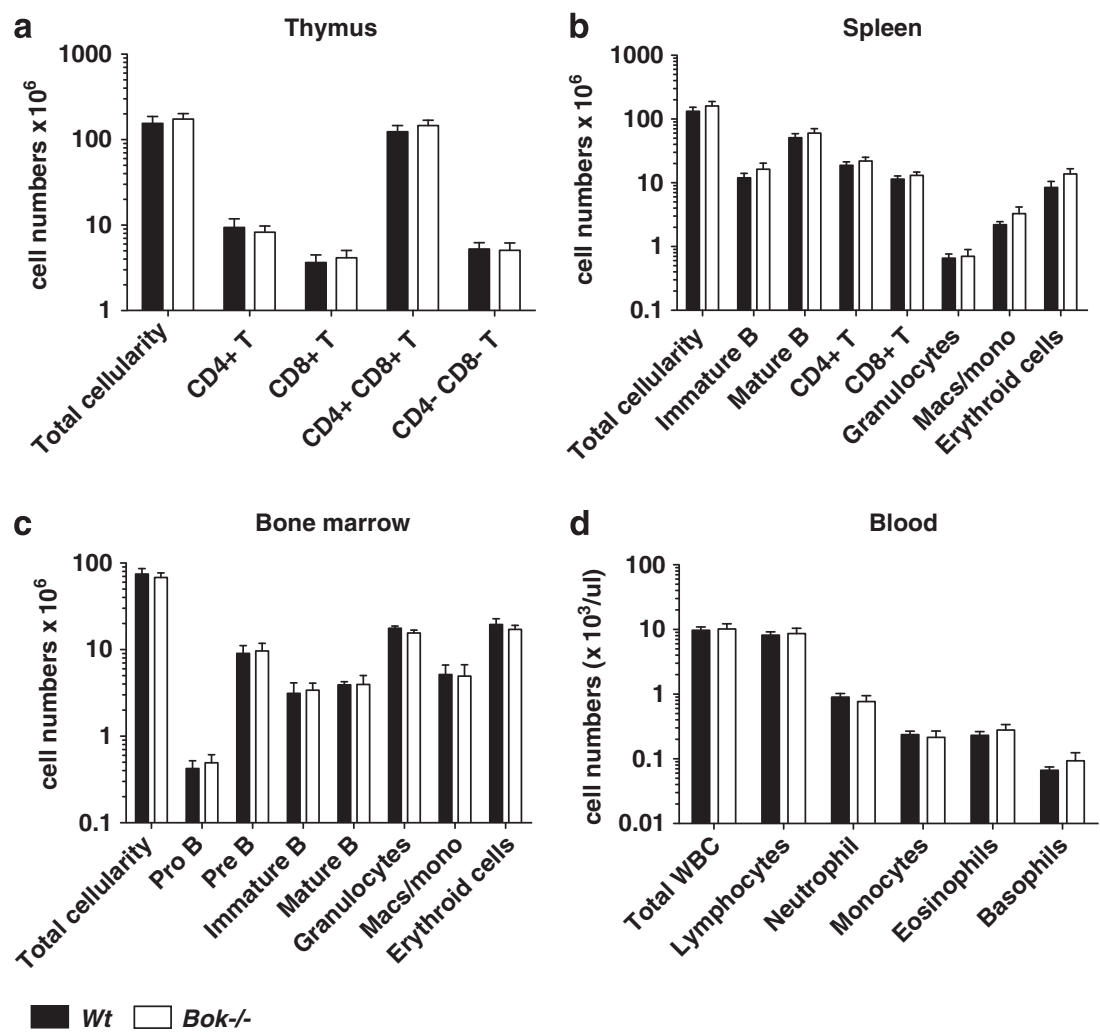

Figure 6 Bok ${ }^{-1-}$ mice have normal hematopoietic cell subset composition. (a) Thymus, (b) spleen and (c) BM were extracted from 9-12-week-old Bok ${ }^{-1-}$ and control wt mice. Single-cell suspensions were prepared, counted, stained with fluorochrome-labelled antibodies against lineage-specific surface markers and analysed by flow cytometry to determine the percentages and (by calculation) numbers of (a) $\mathrm{CD}^{-} \mathrm{CD} 8^{-}, \mathrm{CD} 4^{+} \mathrm{CD}^{+}, \mathrm{CD}^{+}{ }^{+} \mathrm{CD} 8^{-}$and $\mathrm{CD} 4^{-} \mathrm{CD} 8^{+}$thymocytes, $(\mathbf{b}) \mathrm{B}^{2} 20^{+}$slgM $^{\mathrm{hi}}$ slgD ${ }^{\mathrm{low}}$ as well as ${\mathrm{B} 220^{+}} \mathrm{slgM}^{\text {low }}$ slgD ${ }^{\text {hi }}$ mature $\mathrm{B}$ cells, $\mathrm{CD} 4^{+} \mathrm{CD}^{-}$as well as $\mathrm{CD} 4^{-} \mathrm{CD} 8^{+}$mature $\mathrm{T}$ cells, Mac- ${ }^{+}{ }^{+} \mathrm{Gr}-1^{+}$granulocytes, Mac- $1^{+} \mathrm{Gr}-1^{-}$macrophages/monocytes and

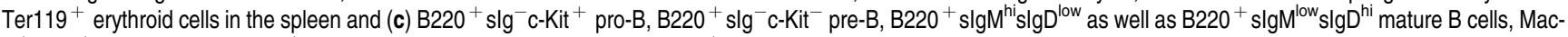
$1^{+} \mathrm{Gr}-1^{+}$granulocytes, Mac-1 ${ }^{+}$Gr-1 ${ }^{-}$macrophages/monocytes and Ter119 ${ }^{+}$nucleated erythroid cells in the bone marrow. (d) Hematopoietic cell subset composition in the blood was determined with an ADVIA automated blood analyser. Results represent mean \pm S.E.M. of the total numbers of cells of a given subset from 9-12-week-old female mice $\left(n=5\right.$ of each genotype). FACS analyses of lymphoid organs from Bok ${ }^{-1-}$ male mice were similarly performed, but these data are not shown

the first investigation of the physiological roles of BOK during development and tissue homeostasis in adulthood. We did not recognise any major developmental abnormalities or phenotypic defects in newborn, adult or aged $\mathrm{Bok}^{-1-}$ mice. Interestingly, Bok-deficient females, but not males, had significantly increased spleen and thymic weights compared with their wt counterparts. Although automated cell counting and FACS analysis did not reveal abnormally elevated numbers of total leukocytes or specific lymphoid/myeloid sub-populations in these tissues, we noticed a trend showing a mild increase across all cell populations that might partly account for this difference in weight. It is currently unclear why a sex-specific lymphoid organ weight increase is observed in our Bok ${ }^{-1-}$ mice, but this might be owing to an indirect effect of hormonal regulation and/or hematopoietic cell extrinsic factors, such as the supporting tissue framework, extracellular matrix or water retention. Notably, it appears that BOK levels in the spleen and thymus are higher in stromal cells than hematopoietic ones.

Despite previous reports suggesting a pro-apoptotic function for BOK, we have yet to observe any developmental abnormalities in BOK-deficient mice indicative of defects in apoptosis. These findings are not unlike those from studies of mice lacking either BAK or BAX alone, which are generally normal and healthy with no major dysfunctions apart from sterility in $\mathrm{Bax}^{-1-}$ males. ${ }^{7,27}$ Moreover, the lymphoid and myeloid cells from $\mathrm{Bax}^{-1-}$ or $\mathrm{Bak}^{-1-}$ mice, like those from our $\mathrm{Bok}^{-1-}$ animals (Figure 7), did not exhibit abnormally increased resistance to apoptotic stimuli in vitro, whereas $\mathrm{Bax}^{-1-} \mathrm{Bak}^{-1-}$ lymphoid cells ${ }^{8}$ and fibroblasts ${ }^{7}$ were profoundly resistant to diverse cytotoxic stressors. These observations suggest that functional overlap may exist between $\mathrm{BOK}$ and $\mathrm{BAX}$ or/and BAK, and this can now be tested by generating $\mathrm{Bok}^{-1-} \mathrm{Bax}^{-1-}, \mathrm{Bok}^{-1-} \mathrm{Bak}^{-1-}$ and eventually also $\mathrm{Bok}^{-1-} \mathrm{Bax}^{-1-} \mathrm{Bak}^{-1-}$ animals. It is, however, also possible that BOK may have a function in a non-apoptotic process (not overlapping with the functions of BAX/BAK). If this was the case, the developmentally programmed cell deaths that still occur in $\mathrm{Bax}^{-1-} \mathrm{Bak}^{-1-}$ mice may be safeguarded by a non-apoptotic cell death program, such as necroptosis. ${ }^{28,29}$

It is also possible that the function of Bok may only manifest under specific circumstances and/or in limited cell types (i.e., those expressing the highest levels of BOK have not yet been examined by in vitro cell survival assays). For instance, on the basis of gene expression analysis, it has been postulated that 


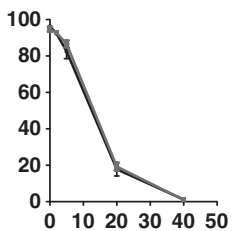

b

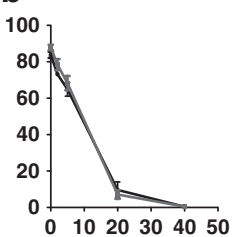

c
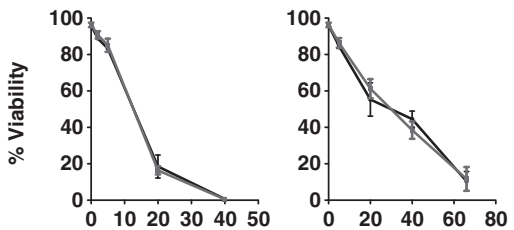

d
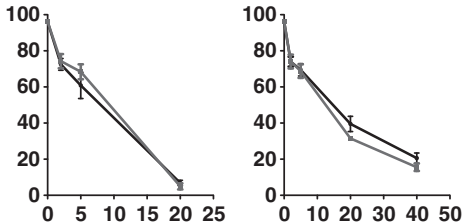

e

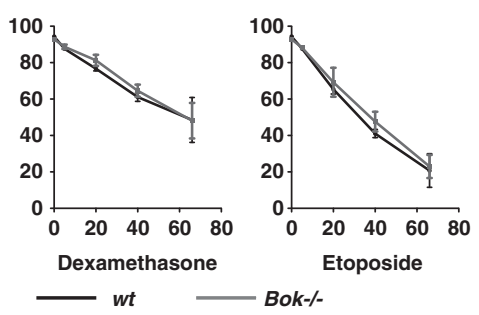

B cells
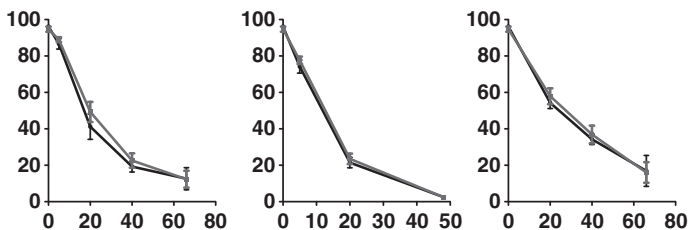

CD4 T cells
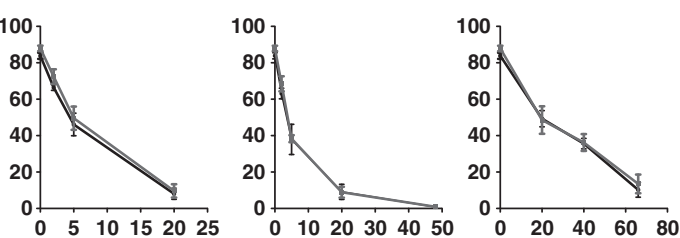

CD8 T cells
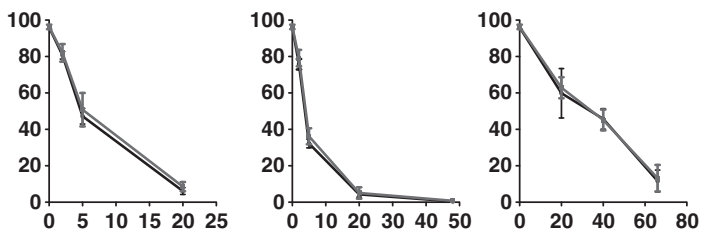

DP T cells
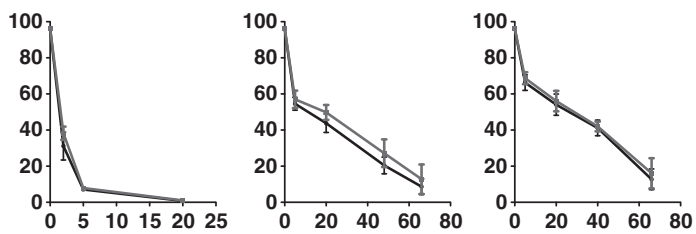

Neutrophils
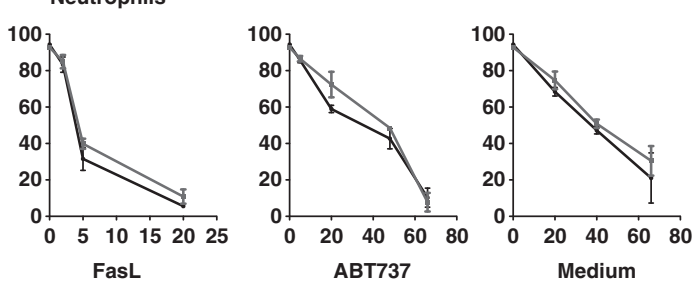

Time (h)

Figure 7 Lymphoid and myeloid cells from $\mathrm{Bok}^{-1-}$ mice are normally sensitive to a broad range of apoptotic stimuli. FACS sorting was used to isolate mature $(\mathrm{a})\left(\mathrm{slg} \mathrm{g}^{+}\right) \mathrm{B}$ cells as well as mature (b) $\mathrm{CD}^{+}{ }^{+} \mathrm{CD} 8^{-}$and $(\mathbf{c}) \mathrm{CD}^{-} \mathrm{CD} 8^{+} \mathrm{T}$ cells from $\mathrm{LN}$ (d) $\mathrm{CD} 4^{+} \mathrm{CD}^{+}$(double positive, $\mathrm{DP}$ ) immature thymocytes from the thymus and (e) Mac$1^{+} \mathrm{Gr}-1^{+}$granulocytes from the BM of 9-14-week-old $\mathrm{Bok}^{-1-}$ and control wt mice. These cells were exposed in tissue culture to a range of apoptotic stimuli, including the glucocorticoid dexamethasone $(1 \mu \mathrm{M})$, etoposide $(1 \mu \mathrm{M})$, crosslinked FasL $(100 \mathrm{ng} / \mathrm{ml})$, the BH3 mimetic ABT-737 $(240 \mathrm{nM})$ and growth factor deprivation (DMEM $+10 \%$ FCS without addition of cytokines). Cell survival was monitored at the indicated times by staining with PI plus FITC-labelled Annexin-V followed by flow cytometric analysis. $\mathrm{PI}^{-}$Annexin- $\mathrm{V}^{-}$cells were regarded as viable cells. Data represent means \pm S.E.M. of data from 4-5 mice of each genotype

Bok may be responsible for the death of placental trophoblast cells under hypoxic conditions in women suffering from preeclampsia. ${ }^{15,16}$ It is noteworthy in this context that the promoter region of mouse and human Bok was found to contain two conserved binding sites for the hypoxia inducible transcription factor HIF- $1 \alpha^{30}$ Accordingly, it will be interesting to examine whether Bok is critical for the death of cells in response to pathological states that cause hypoxia, such as mouse models of stroke or cardiac dysfunction.

A global genomic screen of multiple human cancers found that the Bok gene is localised in a region that is frequently inactivated or deleted during tumourigenesis. ${ }^{17}$ Pertinently, earlier studies have shown that loss of the close relative Bax could accelerate lymphoma development in E $\mu$-myc transgenic mice ${ }^{21}$ as well as SV40 large T-antigen-induced development of brain ${ }^{31}$ or breast cancer ${ }^{32}$ As Bok mRNA and BOK protein could be detected in non-transformed $B$ lymphoid cells (from which $\mathrm{E} \mu$-myc lymphomas arise), ${ }^{26}$ we examined whether its loss could accelerate $\mathrm{E} \mu$-myc-induced lymphomagenesis. We found, however, that Bok deficiency had no impact on the rate of onset, overall incidence or severity of lymphomatous disease in this particular model. 

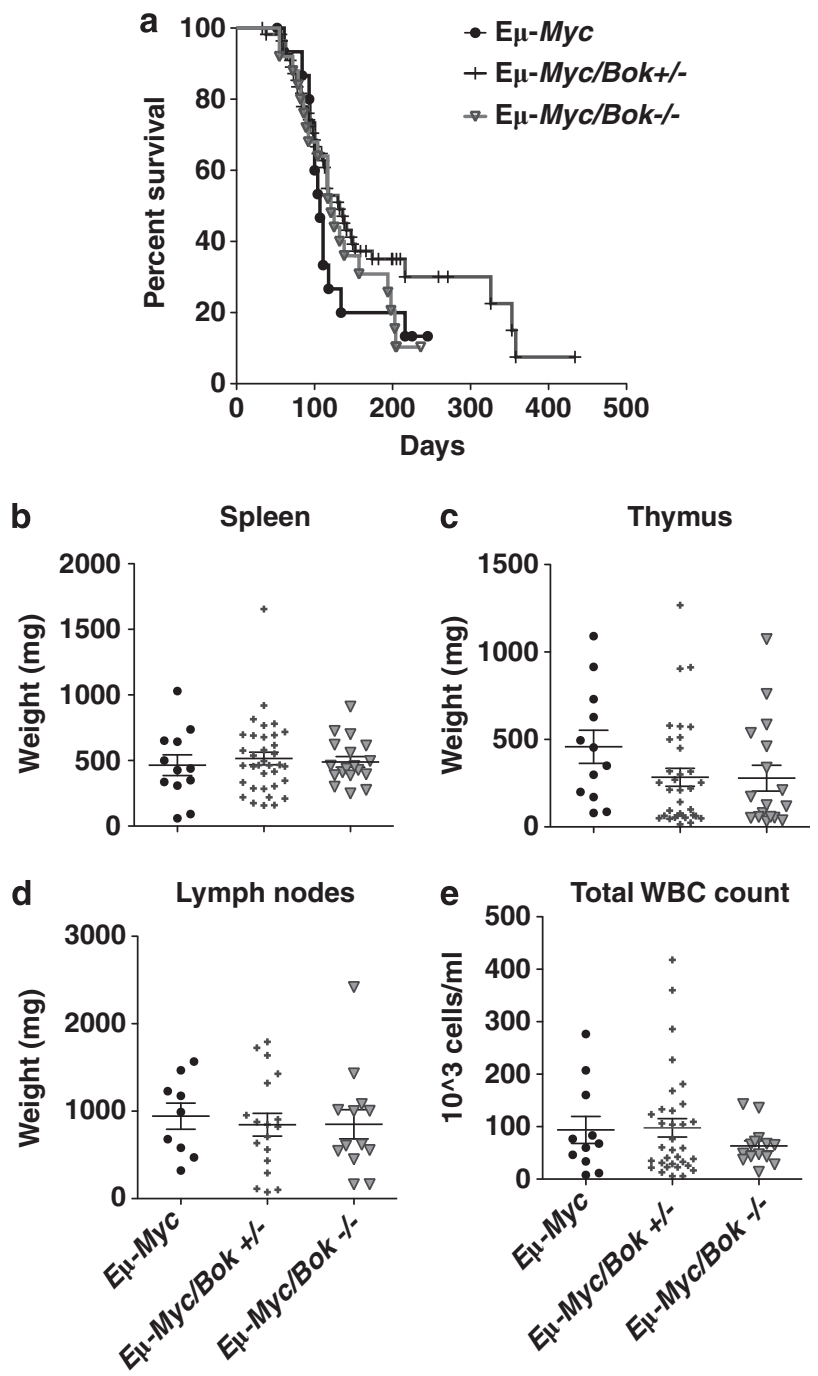

Figure 8 Loss of Bok does not accelerate lymphomagenesis in $\mathrm{E} \mu$-myc transgenic mice. (a) Kaplan-Meier survival curves showing lymphoma-free survival of control $\mathrm{E} \mu$-myc, $\mathrm{E} \mu-\mathrm{myc} / \mathrm{Bok}^{+/-}$and $\mathrm{E} \mu-\mathrm{myc}_{\mathrm{Book}}{ }^{-1}$ mice. No statistically significant differences in survival were observed between mice of the different genotypes $(P=0.303)$. The severity of disease (lymphoma) manifestation in mice of the three different genotypes was determined at time of death by measuring the weights of their (b) spleen, (c) thymus and (d) LN (combined mesenteric, axillary, brachial and inguinal) and determining (e) the numbers of leucocytes in their blood (WBC)

This may imply that Bok does not function as a tumour suppressor, and that therefore loss of a gene located near the Bok gene may account for the selection for somatically acquired copy number loss of this genomic region in human cancers. ${ }^{17}$ Alternatively, Bok may possibly function as a tumour suppressor within the context of certain oncogenic lesions (not those leading to C-MYC over-expression), for example, in cells where it is normally highly expressed, such as the brain or reproductive tissues. A role for BOK in suppressing the development of solid tumours could be addressed by crossing our Bok ${ }^{-1-}$ mice with tumour prone transgenic, knock-out or spontaneous mutant mice (e.g., $A p c^{\mathrm{min}}$ mice), or by subjecting $\mathrm{Bok}^{-1-}$ mice to protocols for chemical mutagen- or viral infection-induced tumourigenesis.
In summary, we conclude that Bok is expressed not only in female reproductive organs as reported previously, ${ }^{12}$ but in a considerably broader range of tissues and cell types. Moreover, our analyses of Bok-deficient mice so far have failed to define a critical function for this BAX/BAK-related $\mathrm{Bcl}-2$ family member, perhaps indicating that its action is largely overlapping with that of those two proteins or that it may be restricted to specific conditions of stress in particular cell types. Our $\mathrm{Bok}^{-1-}$ mice are made freely available for testing its role in such processes and pathological states.

\section{Materials and Methods}

Generation of $\mathrm{Bok}^{-1-}$ mice. The Bok ${ }^{-1-}$ mice were generated by gene targeting in embryonic stem (ES) cells. The targeting vector (Figure 2a) was prepared from C57BL/6 BAC DNA (RP23-262D13) (Australian Genome Research Facility, Melbourne, Australia) by flanking the $1.25 \mathrm{~kb}$ targeted region encompassing half of exon 1 and exon 2 of the Bok gene with LoxP sites, and introducing a Pgk-1 promoter-driven hygromycin resistance cassette flanked by FRT sites. The $5^{\prime}$ - and $3^{\prime}$-arms were $2.54 \mathrm{~kb}$ and $2.37 \mathrm{~kb}$ in length, respectively. A total of $20 \mu \mathrm{g}$ of linearised targeting vector was electroporated into C57BL/6-derived Bruce4 ES cells. Hygromycin-resistant ES clones were screened by Southern blotting with $5^{\prime}$ and $3^{\prime}$ external probes to discriminate between the wt and floxed alleles. DNA from correctly targeted clones was further tested using hybridisation to a PGKhygrospecific probe to confirm single construct integration.

Two recombinant $\mathrm{ES}$ clones carrying the targeted mutation in the Bok gene were injected into C57BL/6 blastocysts, which were subsequently implanted into pseudopregnant $\mathrm{BALB} / \mathrm{c}$ mice. Chimaeric offspring with significant contribution of black fur were crossed to C57BL/6 mice to generate floxed Bok lines, denoted Bok 535 and $B K^{f l} 536$. To check for the targeted allele, genotyping was performed with forward ( $5^{\prime}$-CGGGTTTGAATGGAAGGGTC-3') and reverse primers (5'-TGTTCCCATGGT GCTACATCC- $3^{\prime}$ ) to obtain a 150 and $200 \mathrm{bp}$ product for the wt and floxed allele, respectively.

To generate Bok-deficient mice, heterozygous floxed males $\left(\mathrm{Bok}^{\mathrm{fl}+}\right)$ were crossed to $\mathrm{C} 57 \mathrm{BL} / 6$ deleter females $\left(\mathrm{Cre}^{+}{ }^{+t g}\right)^{33}$ to achieve Cre recombinasemediated excision of the targeted region in all cells. Offspring with a deleted Bok allele $\left(B_{0 k^{+l-}}\right)$ were backcrossed for three generations with C57BL/6 mice and subsequent intercrosses of $\mathrm{Bok}^{+l-}$ mice were set up to generate $\mathrm{Bok}^{+/+}$, $B o k^{+/-}$and Bok ${ }^{-1-}$ mice for analysis. Genotyping of Bok-deficient mice (lines del535 and del536) was performed using a three-primer PCR reaction, utilising a common forward primer ( $5^{\prime}$-CGGGTTTGAATGGAAGGGTC-3') in combination with two reverse primers $\left(5^{\prime}\right.$-TGTTCCCATGGTGCTACATCC- $3^{\prime}$ and $5^{\prime}$-GAGCTAGCTA GCTATGTGTG- $3^{\prime}$ ). Products of 150 and $383 \mathrm{bp}$ were observed when the reaction mixture was separated on a $2 \%$ agarose gel, corresponding to the wt and Bok mutant allele, respectively. PCR primers for the detection of Cre were $5^{\prime}$-CTGA CCGTACACCAAAATTTGCCT-3' (forward) and 5'-GATAATCGCGAACATCTTCA GGTTC-3' (reverse), amplifying a 210 bp product. All experiments with mice were performed according to the guidelines of the animal ethics committees of the Melbourne Health Research Directorate.

Quantitative PCR analysis. RNA was isolated from sorted cells and tissues by homogenisation after addition of TRIzol reagent (Invitrogen, Carlsbad, CA, USA). RNA was quantified using the NanoDrop (Thermo Fisher Scientific, Waltham, MA, USA) technology and $1 \mu \mathrm{g}$ was used for cDNA synthesis using the SuperScript III First-Strand Synthesis SuperMix Kit (Invitrogen) in a 20- $\mu$ reaction volume. PCR amplifications were performed with a $7900 \mathrm{HT}$ thermal cycler (Applied Biosystems, Carlsbad, CA, USA) using $1 \mu \mathrm{l}$ of CDNA and $1 \mu \mathrm{l}$ of Taqman primers (Applied Biosystems) specific for bok (Mm00479421_m1) or ATP5a1 (Mm01257366_m1) in a 96-well plate, under standard running conditions as suggested by the manufacturer. Three replicates of each reaction were performed. All qPCR data were subsequently analysed using the $2^{-\Delta \Delta C T}$ method, ${ }^{34}$ where Atp5 $\alpha 1$ was assigned as the housekeeping gene, and a specific brain sample was designated as the reference sample in all GPCR reactions. This allowed us to compare data between different experiments, where Bok mRNA levels in all samples are presented as the fold difference relative to the same reference sample.

Western blot analysis. Total protein extracts from mouse tissues were prepared in modified RIPA buffer $(50 \mathrm{mM}$ Tris/ $\mathrm{HCl}$ pH $8.0,100 \mathrm{mM} \mathrm{NaCl}, 1 \%$ Triton 
X-100, $1 \%$ sodium deoxycholate, $0.1 \%$ SDS, $5 \mathrm{mM}$ EDTA) complemented with protease inhibitors (Roche (Basel, Switzerland) COMPLETE protease inhibitor cocktail plus $1 \mu \mathrm{g} / \mathrm{ml}$ pepstatin). Protein concentration was determined using a BCA assay (Thermo Fisher Scientific) and $30 \mu \mathrm{g}$ of total protein per extract were resolved by SDS-PAGE. Western blotting was performed using rabbit polyclonal antibodies raised against amino acids 19-32 of $\mathrm{mBOK}$ and, as a loading control, a mouse monoclonal antibody to GAPDH (clone 6C5, Millipore, Billerica, MA, USA).

Histology. Mouse organs were fixed in either 10\% buffered formalin or Bouin's solution and subsequently embedded in paraffin. Histological sections were prepared and stained with haematoxylin/eosin. Whole brains were collected into Bouin's fixative, embedded in paraffin and serial sections prepared for staining with crystal violet dye. Organ sections (including those of brains) were examined with a compound microscope (Zeiss, Oberkochen, Germany) and light microscope (Zeiss), respectively, and photographed with a digital camera (AxioCam HRc Zeiss). From serially sectioned ovaries $\left(n=3-6\right.$ wt or Bok $\left.{ }^{-1}\right)$, follicles containing an oocyte were counted in six equally spaced sections across each ovary and expressed as the mean \pm S.E.M. per $10^{4} \mu \mathrm{m}^{2}\left(\mathrm{~mm}^{2}\right.$ for PN11).

Immunofluorescence staining and flow cytometric analysis. Antibodies used for immunofluorescence staining and FACS analysis or cell sorting included anti-CD4 (YTA321 or H129), anti-CD8 (YTS169), anti-B220 (RA3-6B2), anti-IgM (5.1), anti-IgD (1126C), anti-c-Kit (ACK-4), anti-Mac-1 (MI/70), anti-Gr-1 (RB6-8C5) and anti-Ter119, conjugated to fluorescein isothiocyanate (FITC; Caltag, Buckingham, UK), phycoerythrin (R-PE) or allophycocyanin (APC; both from Prozyme, Hayward, CA, USA). FACS analysis of hematopoietic tissues (spleen, bone marrow, thymus, lymph nodes and blood) was carried out on an LSR1 (Becton Dickinson, Franklin Lakes, NJ, USA) machine and cell sorting was performed using a MoFlo (Cytomation, Boulder, CO, USA) high-speed cell sorter.

Hematopoietic analysis. Peripheral blood was isolated from 8-12-week-old mice by cardiac puncture after euthanasia, and haematological analysis was performed using the ADVIA automated haematology system (Bayer, Tarrytown, NY, USA). Single-cell suspensions were prepared from the thymus, spleen, LN and BM (two tibias and two femurs), and viable cell numbers were enumerated with the automated CASY counter. The cell subset composition of these lymphoid organs was determined by staining with fluorochrome (R-PE, APC or FITC)-conjugated monoclonal antibodies specific to cell lineage markers (see above) and FACS analysis.

Cell culture and cell survival assays. Lymphoid and myeloid cell subsets were isolated by FACS sorting based on their surface marker expression profiles as described above. Immature $\mathrm{CD} 4^{+} \mathrm{CD} 8^{+}$(double-positive, DP) thymocytes were sorted from the thymus, mature $\mathrm{CD} 4^{+} \mathrm{CD} 8^{-}, \mathrm{CD} 4^{-} \mathrm{CD} 8^{+} \mathrm{T}$ cells and mature $\mathrm{B} 22 \mathrm{O}^{+} \mathrm{B}$ cells were sorted from the lymph nodes, and $\mathrm{Gr}-1^{+} \mathrm{Mac}-1^{+}$granulocytes were sorted from the bone marrow. All cells were cultured at $37^{\circ} \mathrm{C}$ in a humidified $10 \%$ CO2 incubator in high-glucose DMEM supplemented with 10\% heatinactivated foetal calf serum (JRH Biosciences, Lenexa, KS, USA), $50 \mu \mathrm{M} 2$ mercaptoethanol, and $100 \mu \mathrm{M}$ asparagine. Sorted cells were cultured in 96-well flat bottom plates at a density ranging between $3-5 \times 10^{5} \mathrm{cell} / \mathrm{s} / \mathrm{ml}$. Apoptotic stimuli applied included dexamethasone $(1 \mu \mathrm{M})$, etoposide $(1 \mu \mathrm{M})$, ABT-737 $(240 \mathrm{nM})$ or FLAG-tagged FasL ( $100 \mathrm{ng} / \mathrm{ml}$; Enzo Life Sciences, Farmingdale, NY, USA) crosslinked with anti-Flag M2 antibody ( $2 \mu \mathrm{g} / \mathrm{ml}$; Sigma, St. Louis, MO, USA). Death by cytokine deprivation was mimicked by plating cells in DMEM $+10 \%$ FCS without the addition of cytokines. To assay for cell survival, cells were stained with $5 \mu \mathrm{g} / \mathrm{ml}$ of propidium iodide (PI) plus FITC-conjugated annexin-V and analysed by flow cytometry at various time intervals. Viable cells were defined as those that were not stained by either PI or FITC-annexin-V $\left(\mathrm{FITC}^{-} \mathrm{PI}^{-}\right)$.

Statistical analysis. All statistical analyses were performed using the twotailed Student's $t$-test, and $P$-values $<0.5$, were considered significant.

\section{Conflict of Interest}

The authors declare no conflict of interest.

Acknowledgements. We thank Drs JM Adams, S Cory, DCS Huang, D Gray, M Herold and G Kelly for mice, reagents and advice; K Vella, G Siciliano, D Cooper, $\mathrm{N}$ lannarella and J Coughlin for animal care; J Corbin for automated blood analysis; B Helbert and C Young for genotyping; E Tsui for histological preparations; Dr. F
Battye and his team for cell sorting; D Quilici, T Nikolaou and G Thomas for irradiation and $D$ Bachmann for expert technical assistance. This work was supported by grants and fellowships from the Leukemia Research Foundation (to FK), the National Health and Medical Research Council (Program Grant no. 461221, NHMRC Australia Fellowship), the NIH (CA43540), the Leukemia and Lymphoma Society (SCOR grant no. 7413), the Swiss National Science Foundation (to TK, PP0033_119203) and operational infrastructure grants through the Australian Government IRISS and the Victorian State Government OIS.

1. Youle RJ, Strasser A. The BCL-2 protein family: opposing activities that mediate cell death Nat Rev Mol Cell Biol 2008; 9: 47-59.

2. Chipuk JE, Green DR. How do BCL-2 proteins induce mitochondrial outer membrane permeabilization? Trends Cell Biol 2008; 18: 157-164.

3. Huang DCS, Strasser A. BH3-only proteins - essential initiators of apoptotic cell death. Cell 2000; 103: 839-842.

4. Letai AG. Diagnosing and exploiting cancer's addiction to blocks in apoptosis. Nat Rev Cancer 2008; 8: 121-132.

5. Willis SN, Fletcher Jl, Kaufmann T, van Delft MF, Chen L, Czabotar PE et al. Apoptosis initiated when $\mathrm{BH} 3$ ligands engage multiple Bcl-2 homologs, not Bax or Bak. Science 2007; 315: 856-859.

6. Merino D, Giam M, Hughes PD, Siggs OM, Heger K, O'Reilly LA et al. The role of BH3-only protein Bim extends beyond inhibiting Bcl-2-like prosurvival proteins. J Cell Biol 2009; 186 355-362.

7. Lindsten T, Ross AJ, King A, Zong W, Rathmell JC, Shiels HA et al. The combined functions of proapoptotic Bcl-2 family members Bak and Bax are essential for normal development of multiple tissues. Mol Cell 2000; 6: 1389-1399.

8. Rathmell JC, Lindsten T, Zong W-X, Cinalli RM, Thompson CB. Deficiency in Bak and Bax perturbs thymic selection and lymphoid homeostasis. Nat Immunol 2002; 3: 932-939.

9. Zong WX, Lindsten T, Ross AJ, MacGregor GR, Thompson CB. BH3-only proteins that bind pro-survival $\mathrm{Bcl}-2$ family members fail to induce apoptosis in the absence of Bax and Bak. Genes Dev 2001; 15: 1481-1486.

10. Cheng EH, Wei MC, Weiler S, Flavell RA, Mak TW, Lindsten T et al. BCL-2, BCL-X sequester $\mathrm{BH} 3$ domain-only molecules preventing $\mathrm{BAX}$ - and $\mathrm{BAK}$-mediated mitochondria apoptosis. Mol Cell 2001; 8: 705-711.

11. Strasser A, Harris AW, Huang DCS, Krammer PH, Cory S. Bcl-2 and Fas/APO-1 regulate distinct pathways to lymphocyte apoptosis. EMBO J 1995; 14: 6136-6147.

12. Hsu SY, Kaipia A, McGee E, Lomeli M, Hsueh AJW. Bok is a pro-apoptotic Bcl-2 protein with restricted expression in reproductive tissues and heterodimerizes with selective anti-apoptotic Bcl-2 family members. Proc Natl Acad Sci USA 1997; 94: 12401-12406.

13. Hsu SY, Hsueh AJW. A splicing variant of the Bcl-2 member Bok with a truncated $B H 3$ domain induces apoptosis but does not dimerize with antiapoptotic $\mathrm{Bcl}-2$ proteins in vitro. J Biol Chem 1998; 273: 30139-30146.

14. Inohara N, Ekhterae D, Garcia I, Carrio R, Merino J, Merry A et al. Mtd, a novel Bcl-2 family member activates apoptosis in the absence of heterodimerization with Bcl-2 and Bcl- $\mathrm{x}_{\mathrm{L}}$. J Biol Chem 1998; 273: 8705-8710.

15. Ray JE, Garcia J, Jurisicova A, Caniggia I. Mtd/Bok takes a swing: proapoptotic Mtd/Bok regulates trophoblast cell proliferation during human placental development and in preeclampsia. Cell Death Differ 2010; 17: 846-859.

16. Soleymanlou N, Wu Y, Wang JX, Todros T, letta F, Jurisicova A et al. A novel Mtd splice isoform is responsible for trophoblast cell death in pre-eclampsia. Cell Death Differ 2005 12: $441-452$

17. Beroukhim R, Mermel C, Porter D, Wei G, Raychaudhuri S, Donovan J et al. The landscape of somatic copy-number alteration across human cancers. Nature 2010; 463: 899-905.

18. Deckwerth TL, Elliott JL, Knudson CM, Johnson Jr EM, Snider WD, Korsmeyer SJ. BAX is required for neuronal death after trophic factor deprivation and during development Neuron 1996; 17: 401-411.

19. Bouillet P, Metcalf D, Huang DCS, Tarlinton DM, Kay TWH, Köntgen F et al. Proapoptotic $\mathrm{Bcl}-2$ relative Bim required for certain apoptotic responses, leukocyte homeostasis, and to preclude autoimmunity. Science 1999; 286: 1735-1738.

20. Villunger A, Michalak EM, Coultas L, Müllauer F, Böck G, Ausserlechner MJ et al. p53- and drug-induced apoptotic responses mediated by $\mathrm{BH} 3-$ only proteins Puma and Noxa. Science 2003; 302: 1036-1038.

21. Eischen CM, Roussel MF, Korsmeyer SJ, Cleveland JL. Bax loss impairs Myc-induced apoptosis and circumvents the selection of p53 mutations during Myc-mediated lymphomagenesis. Mol Cell Biol 2001; 21: 7653-7662.

22. Egle A, Harris AW, Bouillet $P$, Cory $S$. Bim is a suppressor of Myc-induced mouse $B$ cell leukemia. Proc Natl Acad Sci USA 2004; 101: 6164-6169.

23. Hemann MT, Zilfou JT, Zhao Z, Burgess DJ, Hannon GJ, Lowe SW. Suppression of tumorigenesis by the p53 target PUMA. Proc Natl Acad Sci USA 2004; 101: 9333-9338.

24. Garrison SP, Jeffers JR, Yang C, Nilsson JA, Hall MA, Rehg JE et al. Selection against PUMA gene expression in Myc-driven B-cell lymphomagenesis. Mol Cell Biol 2008; 28 : 5391-5402.

25. Michalak EM, Jansen ES, Happo L, Cragg MS, Tai L, Smyth GK et al. Puma and to a lesser extent Noxa are suppressors of Myc-induced lymphomagenesis. Cell Death Differ 2009; 16: 684-696. 
26. Adams JM, Harris AW, Pinkert CA, Corcoran LM, Alexander WS, Cory S et al. The c-myc oncogene driven by immunoglobulin enhancers induces lymphoid malignancy in transgenic mice. Nature 1985; 318: 533-538.

27. Knudson CM, Tung KSK, Tourtellotte WG, Brown GAJ, Korsmeyer SJ. Bax-deficient mice with lymphoid hyperplasia and male germ cell death. Science 1995; 270: 96-99.

28. Hotchkiss RS, Strasser A, McDunn JE, Swanson PE. Cell death. N Engl J Med 2009; 361: 1570-1583

29. Degterev A, Yuan J. Expansion and evolution of cell death programmes. Nat Rev Mol Cell Biol 2008; 9: 378-390.

30. Gao S, Fu W, Durrenberger M, De Geyter C, Zhang H. Membrane translocation and oligomerization of hBok are triggered in response to apoptotic stimuli and Bnip3. Cell Mol Life Sci 2005; 62: 1015-1024.
31. Yin CY, Knudson CM, Korsmeyer SJ, Van Dyke T. Bax suppresses tumorigenesis and stimulates apoptosis in vivo. Nature 1997; 385: 637-640.

32. Shibata MA, Liu ML, Knudson MC, Shibata E, Yoshidome K, Bandey T et al. Haploid loss of bax leads to accelerated mammary tumor development in C3(1)/SV40-TAg transgenic mice: reduction in protective apoptotic response at the preneoplastic stage. EMBO J 1999; 18: 2692-2701.

33. Schwenk F, Baron U, Rajewsky K. A cre-transgenic mouse strain for the ubiquitous deletion of loxP-flanked gene segments including deletion in germ cells. Nucleic Acids Res 1995; 23: 5080-5081.

34. Livak KJ, Schmittgen TD. Analysis of relative gene expression data using real-time quantitative PCR and the 2(-Delta Delta C(T)) Method. Methods 2001; 25: $402-408$.

Supplementary Information accompanies the paper on Cell Death and Differentiation website (http://www.nature.com/cdd) 